University of Nebraska - Lincoln DigitalCommons@University of Nebraska - Lincoln

2016

\title{
Compositional effects on the cyclic oxidation resistance of conventional superalloys
}

James L. Smialek

NASA Glenn Research Center, james.1.smialek@nasa.gov

Peter J. Bonacuse

NASA Glenn Research Center

Follow this and additional works at: http://digitalcommons.unl.edu/nasapub

Smialek, James L. and Bonacuse, Peter J., "Compositional effects on the cyclic oxidation resistance of conventional superalloys" (2016). NASA Publications. 223.

http://digitalcommons.unl.edu/nasapub/223

This Article is brought to you for free and open access by the National Aeronautics and Space Administration at DigitalCommons@University of Nebraska - Lincoln. It has been accepted for inclusion in NASA Publications by an authorized administrator of DigitalCommons@University of Nebraska - Lincoln. 


\title{
Compositional effects on the cyclic oxidation resistance of conventional superalloys
}

\author{
James L. Smialek* (1) and Peter J. Bonacuse
}

The $1100{ }^{\circ} \mathrm{C}$ cyclic oxidation performance of $25 \mathrm{Ni}$-base commercial and developmental alloys was compiled from an extensive database and ranked according to the $200 \mathrm{~h}$ weight change. Cyclic oxidation performance of superalloys is directly controlled by composition. These conventionally cast superalloys were composed of base elements [Ni-Co-Cr-Al], refractory elements [Nb-Mo-Ta-W], oxygen-active elements [Ti-Zr-Hf], light elements [B,C], and occasionally [V-Mn-Si], with $\mathrm{P}$ and $\mathrm{S}$ trace impurities. The oxidation results were broadly categorised as less than $4 \mathrm{mg} / \mathrm{cm}^{2}$ weight loss for alloys with high 5-6\% Al and 3-9\% Ta, and with low $\leq 1 \% \mathrm{Ti}$ (wt.\%). Conversely, weight loss of 200-300 mg/ $\mathrm{cm}^{2}$ characterised alloys containing low $<3.5 \% \mathrm{Al}$, no Ta, and high $>3 \% \mathrm{Ti}$. These trends correlated with beneficial and detrimental scale phases previously reported. An unambiguous $\mathrm{Cr}$ effect was masked because of its strongly coupled, but inverse, correlation with Al. Multiple linear regression was used to fit alloy composition to a simple logarithmic weight change transform. The function contained 10 terms and yielded a correlation coefficient, $r^{2}$, of 0.84 . Various graphical representations helped to further illustrate, quantify, and predict complex oxidation effects within a 10-element compositional space.

Keywords: Superalloys, Cyclic oxidation, Compositional effects, Scale phases

\section{Introduction}

\section{General premise and purpose}

The high temperature environmental degradation of Ni-base superalloys in oxidising atmospheres is generally described in terms of scaling and spallation rates. To this end, both isothermal and cyclic oxidation tests perform a useful role. The degree of metal consumption is a primary indicator of surface recession and loss of load bearing material, although the morphology and amount of internal oxidation is also extremely important. The specific weight (mass) change is one indicator of the degree of attack. Characterisation of the scale chemistry and oxide phases provide further useful details, as do the microstructural aspects of the attack, (i.e. uniform layer vs. internal protrusions). Historically, many of the existing conventionally cast commercial alloys may have been designed primarily for yield strength or creep resistance, with somewhat less emphasis on oxidative behaviour. Nevertheless, there exists a broad range of compositional design that affects oxidation. This relationship between composition and oxidation behaviour of conventional superalloys is of interest and forms the focus of this study. The results for a wide collection of alloys were extracted from an extensive database that utilised common cyclic oxidation test methods. Other studies have used model alloys to study a specific design space and compositional effects. Great progress has also been made in the more recent class of oxidation resistant single crystal superalloys. Both of these latter topics deserve attention; however, a thorough integration is beyond the scope of the present demonstration.

Materials and Structures Division, NASA Glenn Research Center, Cleveland, $\mathrm{OH}, \mathrm{USA}$

*Corresponding author. email james.I.smialek@nasa.gov
Much of the historical perspective serving as background to the present paper has been presented in a number of overviews. ${ }^{1-3}$ Briefly, the primary basis for describing oxidation behaviour is in terms of isothermal and cyclic $\mathrm{Ni}-\mathrm{Cr}-\mathrm{Al}$ oxide maps, as produced for example by Giggins and Pettit (isothermal) or Barrett and Lowell (cyclic). ${ }^{4,5}$ These oxide maps define the ternary compositional space defining regimes of fast growing $\mathrm{NiO}$, beneficial slow growing protective external vs. detrimental non-protective internal $\mathrm{Al}_{2} \mathrm{O}_{3}$, and less protective $\mathrm{Cr}_{2} \mathrm{O}_{3}$ (or some combination thereof, including $\mathrm{Ni}(\mathrm{Al}, \mathrm{Cr})_{2} \mathrm{O}_{4}$ spinels). Given this as a basis, the oxidative behaviour can then tolerate low levels of various alloying additions generally needed for strengthening, such as refractory elements. $\mathrm{Cr}$ and Al levels may then need further adjustment to counter any detriment. But higher levels of strengthening elements eventually yield new detrimental scale phases based on the additions. However, this paper will not dwell on detailed mechanisms, but will attempt to highlight broad compositional trends on performance. One primary attribute of the present study is the presentation and comparison of prior results obtained for a wide variety of commercially available conventional materials, all tested with identical protocols. Ultimately, some rudimentary comparisons can also be drawn between single crystal alloys and powder metallurgy disk alloys. While single crystals are normally used for airfoils, they have been proposed for external rims in a novel hybrid turbine disk concept currently being explored by NASA.

\section{Cyclic oxidation testing protocols}

Cyclic oxidation had been performed by fundamentally the same technique for the vast majority of samples in the referenced database, as described in the associated references. ${ }^{5-12}$ 
Vertical FeCrAlZr - wound electric furnaces were used, having six symmetrically arranged alumina tubes ( $35 \mathrm{~mm}$ i.d.) around the core. Nominally, $1.3 \times 2.5 \mathrm{~cm}$ rectangular samples were hung by Pt wires and lowered into (and raised out of) the $\sim 10 \mathrm{~cm}$ hot zone of the tubes via timers/solenoids and a pneumatic piston drive mechanism. Temperature profiling by thermocouple at the specimen location indicated them to be typically within $\pm 2{ }^{\circ} \mathrm{C}$ of the target temperature. Cycling procedure was fixed at same sequence of $1 \mathrm{~h}$ heat, 20 mins cool for all test data used here. Heating typically took less than 5 mins to reach temperature and approximately 10 mins to cool below $100{ }^{\circ} \mathrm{C}$. Samples were generally removed for daily inspection/weighing.

\section{Prior studies: alloy composition, scale phases and performance}

By way of specific examples, the isothermal and cyclic behaviour of four superalloys had been examined in some detail. ${ }^{6}$ In Table 1, it can be seen that these alloys are primarily $\mathrm{Ni}-\mathrm{Cr}-\mathrm{Al}$-based with varying amounts of $\mathrm{Ti}, \mathrm{Nb}$, $\mathrm{Mo}$, Ta and $\mathrm{W}$. The final weight change after $1001 \mathrm{~h}$ cycles at $1100{ }^{\circ} \mathrm{C}$ shows better performance for $\mathrm{Al}>5 \%$ and $\mathrm{Ta}>4 \%$, with poor performance for $\mathrm{Ti}>3 \%$ and perhaps for $\mathrm{Cr}>13 \%$. Trends with $\mathrm{Nb}, \mathrm{Mo}$, W were less apparent, if present. Semi-quantitative analyses of the scale phases vs. time were determined by high-temperature X-ray diffraction using bulk oxide mixtures as standards in a careful study of scale phases. $^{7}$ The results shown in Table 2 indicated a predominance of $\alpha-\mathrm{Al}_{2} \mathrm{O}_{3}, \mathrm{Ni}(\mathrm{Al}, \mathrm{Cr})_{2} \mathrm{O}_{4}$ spinel, and $\mathrm{NiTa}_{2} \mathrm{O}_{6}$ tri-rutile for the alloys exhibiting the least weight change, and $\alpha-\mathrm{Cr}_{2} \mathrm{O}_{3}, \mathrm{NiCr}_{2} \mathrm{O}_{4}$ spinel, $\mathrm{NiO}$ and $\mathrm{NiTiO}_{3}$ for the higher weight changes.

The ratio, $\mathrm{R}_{\mathrm{A} /(\mathrm{A}+\mathrm{B})}$, of the beneficial scale phase group $A$ to the sum of A plus the detrimental group $B$ can be determined from Table 2 . It is seen to follow the ratio $\mathrm{R}_{\mathrm{A} /(\mathrm{A}+\mathrm{B})}$ of the corresponding alloying elements, $(\mathrm{Al}+\mathrm{Ta}) /(\mathrm{Al}+\mathrm{Ta}+\mathrm{Cr}+\mathrm{Ti})$, where each element was normalised by its atomic weight, shown as circles in Fig. 1. Here, isothermal X-ray diffraction data were used instead of cyclic data to avoid any inconsistencies arising from the loss of some scale phases during spalling. Furthermore, the cyclic oxidation weight change behaviour tracks the alloy ratio in a parallel form, as shown by the triangles. Thus, beneficial and detrimental scale phases are implied, as they are associated with minimal or excessive oxidation attack, respectively. The trends shown thus help quantify correlations between alloy content, scale make-up and performance. These trends are simply assumed to result primarily from the relative growth rates of the specific oxide phases and spallation rates that generally increase with scale thickness. It is not believed that the mechanical properties of the scales or alloys result in a first-order effect on oxidation performance.

While not specifically identified in that particular study, it is also recognised that $\mathrm{NiMoO}_{4}, \mathrm{NiWO}_{4}, \mathrm{CrNbO}_{4}$ and $\mathrm{V}_{2} \mathrm{O}_{5}$ (liquid above $690{ }^{\circ} \mathrm{C}$ ) are fast growing or detrimental, from previous literature covering a wider alloy and testing base. The question of protective $\mathrm{Cr}_{2} \mathrm{O}_{3}$ will appear as an issue throughout this paper. At this point, suffice it to say that, coupled with appreciable $\mathrm{NiO}$ in the scale, $\mathrm{Cr}_{2} \mathrm{O}_{3}$ does not provide adequate performance at the elevated temperature of $1100{ }^{\circ} \mathrm{C}$. At lower use temperatures, for which many of these alloys were originally designed, $\mathrm{Cr}_{2} \mathrm{O}_{3}$ scales provide more effective protection, as would be more consistent with prevailing concepts.

Similarly, the beneficial effect of Ta is unexpected. Ta may serve to prevent the detrimental effects of $\mathrm{NiO}$ by reacting with $\mathrm{Ni}$ to form $\mathrm{NiTa}_{2} \mathrm{O}_{6}$. The latter appears to be innocuous in the numerous studies of superalloys reviewed previously. It may also be significant that this phase appears, not as a continuous layer or through-phase, but as small $\mu \mathrm{m}$-sized spherical dispersoids in the $\alpha-\mathrm{Al}_{2} \mathrm{O}_{3}$ layer. In any event, the exact mechanism has not been conclusively identified.

\section{Attack parameter and COSP model}

The degree of weight change will be used as a figure of merit in comparing alloy performance. It is not only controlled by how fast the scale grows, but how much spalls off when thermally cycled. To this end, Barrett had initially devised an attack parameter, $K_{\mathrm{a}}$, that correlated with material loss. It accounts for an initial parabolic growth rate $k_{\mathrm{p}}$ combined with a terminal linear rate of spalling $\mathrm{k}_{\mathrm{l}}$, and its empirical coefficient found to be $\sim 10$ according to ${ }^{8}$ :

Table 1 Composition and $1100{ }^{\circ} \mathrm{C}, 100 \mathrm{~h}$ cyclic oxidation weight change of four Ni-base superalloys. (from Barrett, Santoro, Lowell, 1973 [Ref. 6]). Note higher Cr is not able to overcome the deficiency of lower Al for IN 738

\begin{tabular}{|c|c|c|c|c|c|c|c|c|}
\hline Alloy & $\mathrm{Al}$ & $\mathrm{Ta}$ & $\mathrm{Ti}$ & $\mathrm{Cr}$ & $\mathrm{Nb}$ & Mo & W & $\mathrm{mg} / \mathrm{cm}^{2}$ \\
\hline B1900 & 6.2 & 4.3 & 1.1 & 8.0 & 0.1 & 6.0 & 0.1 & -0.60 \\
\hline NASA TRW VIA & 5.3 & 9.0 & 1.0 & 5.9 & 0.5 & 2.0 & 5.8 & -0.68 \\
\hline IN 713 & 6.0 & 0.0 & 0.9 & 13.9 & 2.0 & 4.5 & 0.0 & -4.71 \\
\hline IN 738 & 3.6 & 1.8 & 3.4 & 15.8 & 0.9 & 1.8 & 2.6 & -27.56 \\
\hline
\end{tabular}

Table 2 High temperature XRD of scale make-up (from relative intensities and standards) for four superalloys oxidised at $1100{ }^{\circ} \mathrm{C}$ for $100 \mathrm{~h}$. Data from Garlick and Lowell ${ }^{7}$. Note the XRD ratio $\mathrm{R}_{\mathrm{A} /(\mathrm{A}+\mathrm{B})}^{\prime}$ reflects the partitioning of beneficial scale phases

\begin{tabular}{|c|c|c|c|c|c|c|c|c|c|c|c|c|}
\hline Isothermal & $\mathrm{Al}_{2} \mathrm{O}_{3}$ & $\mathrm{NiAl}_{2} \mathrm{O}_{4}$ & $\mathrm{Ni}(\mathrm{Al}, \mathrm{Cr})_{2} \mathrm{O}_{4}$ & $\mathrm{NiTa}_{2} \mathrm{O}_{6}$ & sum $A$ & $\mathrm{Cr}_{2} \mathrm{O}_{3}$ & $\mathrm{NiCr}_{2} \mathrm{O}_{4}$ & $\mathrm{NiO}$ & $\mathrm{NiTiO}_{3}$ & sum B & $A /(A+B)$ ratio & $\mathrm{mg} / \mathrm{cm}^{2}$ \\
\hline B1900 & 5 & 19 & 3 & 0.8 & 27.8 & trace & 2 & 0.2 & 0 & 2.2 & 0.93 & 0.49 \\
\hline IVA & 3 & 10 & 2 & 1.4 & 16.4 & 0.2 & 0 & 0.1 & trace & 0.3 & 0.98 & 1.51 \\
\hline IN 713 & 2.8 & 22.2 & 0 & 0.7 & 25.7 & 0 & 2.8 & 0.7 & 0 & 3.5 & 0.88 & 0.69 \\
\hline IN 738 & 0 & 0 & 0 & 0 & 0 & 0 & 9 & 6.5 & 2.6 & 18.1 & 0.00 & 4.01 \\
\hline \multicolumn{13}{|l|}{ Cyclic } \\
\hline B1900 & 1.75 & 15 & 5 & 0.7 & 22.45 & 0 & 0 & 0.3 & 0 & 0.3 & 0.99 & -0.60 \\
\hline IVA & 2.5 & 8.6 & 1.4 & 1.5 & 14 & 0.15 & 0 & 1.2 & trace & 1.35 & 0.91 & -0.68 \\
\hline IN 713 & 1.15 & 10.8 & 7.2 & 0.3 & 19.45 & 0.3 & 0 & 2.25 & 0 & 2.55 & 0.88 & -4.71 \\
\hline IN 738 & 0 & 0.8 & 1.6 & 0.25 & 2.65 & 0.3 & 1.6 & 3.5 & 0 & 5.4 & 0.33 & -27.56 \\
\hline
\end{tabular}




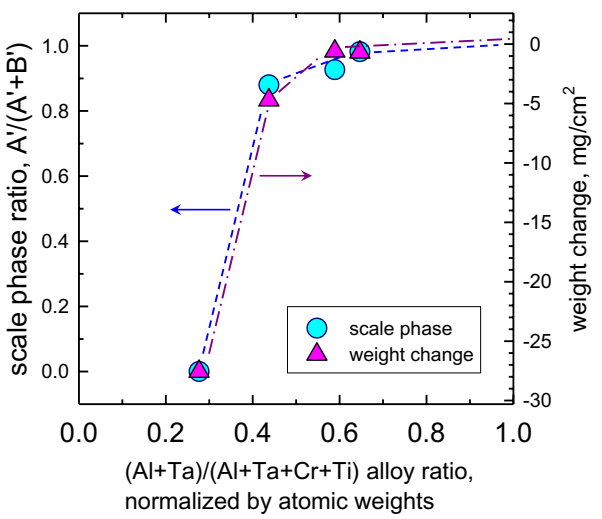

1 Effect of alloy composition on scale phases and cyclic oxidation at $1100{ }^{\circ} \mathrm{C}, 100 \mathrm{~h}$. Isothermal scale phase Type $\mathrm{A}\left(\mathrm{Al}_{2} \mathrm{O}_{3}+\mathrm{NiAl}_{2} \mathrm{O}_{4}+\mathrm{NiTa}_{2} \mathrm{O}_{6}\right)$ and Type $\mathrm{B}$ $\left(\mathrm{Cr}_{2} \mathrm{O}_{3}+\mathrm{NiCr}_{2} \mathrm{O}_{4}+\mathrm{NiO}+\mathrm{NiTiO}_{3}\right)$ presented as (a) a function of alloy ratio, $\mathrm{R}_{\mathrm{A} /(\mathrm{A}+\mathrm{B})}=(\mathrm{Al}+\mathrm{Ta}) /(\mathrm{Al}+\mathrm{Ta}+\mathrm{Cr}+\mathrm{Ti})$, and (b) parallel cyclic weight change response

$$
K_{\mathrm{a}}=k_{\mathrm{p}} \frac{1}{2}+10\left|k_{1}\right|
$$

This parameter is then correlated with composition using multiple linear regression statistical techniques. Some predictions of elemental effects have been reviewed previously, consistent with the discussions in this paper. ${ }^{2}$ However, insofar as $K_{\mathrm{a}}$ is a combination of two oxidation constants, it is not readily converted to a recognisable measured quantity, e.g. weight change. Similarly, phenomenological, fitted cyclic oxidation model curves could produce intrinsic growth and spalling parameters and an estimate of the amount of metal consumed, the preferred figure of merit, e.g. COSP. ${ }^{9}$ However, this too requires modelling and choices regarding oxide phases and spall morphology.

Furthermore, at $1100^{\circ} \mathrm{C}$, the weight increase portion of the curve is often minimal, with many alloys beginning to lose weight immediately, as will be shown below. Thus, the final weight change may suffice as a meaningful and convenient figure of merit. While it is a complex function of the amount of scale growth and the fraction of scale spalled each cycle, it is the most familiar and easily measured quantity. This then will be used in the present analysis for a suite of alloys all tested in the same $1100^{\circ} \mathrm{C}, 1 \mathrm{~h}$ cycle, furnace cycling test available in the Barrett database. The objective will be to extract general compositional trends in the cyclic oxidation of common cast Ni-base superalloys using a combination of tabular, graphical, and regression techniques.

\section{Scale adhesion, dopants and impurities}

Since these alloys were developed prior to the use of strong reactive element $(\mathrm{Y})$ or reduced sulphur effects on $\mathrm{Al}_{2} \mathrm{O}_{3}$ scale adhesion for superalloys, no compositional parameter was introduced to account for these as independent variables. At best, the reactive element Hf was present in some of the alloys at a level of $0.4-1.5 \%$, so it was included in the multiple linear regression analyses, as was carbon present at $0.05-0.2 \%$ in most alloys.

\section{Results-experimental data and analysis Summary ranking table}

A representative collection of 25 primarily commercial superalloys is presented in Table 3, all tested by the same procedure in an $1100{ }^{\circ} \mathrm{C}$ cyclic oxidation furnace test for 200 $1 \mathrm{~h}$ cycles. ${ }^{10-12}$ The alloys are ordered by final weight change and presented along with major alloying constituents. Such constructs have been referred to as ranking diagrams. They allow a first-level inspection of any compositional effects. In this test, the alloys were widely discriminated, showing the top ranking alloy NASA TAZ-8A at $+0.56 \mathrm{mg} / \mathrm{cm}^{2}$, the bottom alloy Rene' 80 at $-330 \mathrm{mg} / \mathrm{cm}^{2}$, with Rene' 120 near the median at $-39 \mathrm{mg} / \mathrm{cm}^{2}$. Among just these three alloys it can be seen that $\mathrm{Al}, \mathrm{Ta}$ and $\mathrm{Nb}$ decrease and $\mathrm{Cr}$ and $\mathrm{Ti}$ increase for more severe weight losses, with less transparent trends for Mo and W.

From a wider perspective, all the alloys above the median contain at least $5.0 \% \mathrm{Al}$, though higher $\mathrm{Al}$ on its own does not necessarily guarantee better oxidation resistance. Of these, the top six alloys contain between 6 and $8 \%$ Cr. However, higher $\mathrm{Cr}$ is no guarantee of better performance as six alloys with over $10 \% \mathrm{Cr}$ reside in the bottom half of the diagram. Low $0-1 \% \mathrm{Ti}$ appears to correlate with better performance (top seven positions), along with higher 3-9\% Ta. The picture is not very clear for $\mathrm{Nb}$, Mo or $\mathrm{W}$ trends from this data-set, except perhaps that the two alloys with $18 \%$ Mo or W reside in the lower half. As a summary figure of merit, the $\mathrm{R}_{(\mathrm{Al}+\mathrm{Ta})(\mathrm{Al}+\mathrm{Ta}+\mathrm{Cr}+\mathrm{Ti})}$ ratios, normalised by atomic weights as in Fig. 1, are also listed. These show that the top ranking six alloys all have higher $R$ values of $0.5-0.7$. Conversely, seven alloys with low $R$ values of $0.14-0.33$ all reside in the lower half of this table. (Note that \#1 TAZ 8A contains no $\mathrm{V}$, whereas \#21 TAZ 8 contains $2.5 \% \mathrm{~V}$, known to be extremely detrimental to oxidation resistance).

\section{Cyclic oxidation curves of selected alloys}

The behaviour of 10 representative alloys is now discussed for the least, median and greatest weight losses, Table 4, and includes the four alloys of Table 1 . The $1100{ }^{\circ} \mathrm{C}$ cyclic oxidation behaviour of the first five alloys, Fig. $2 a$, exhibit well-behaved curves, ranging from a small weight gain to a $-6 \mathrm{mg} / \mathrm{cm}^{2}$ loss. The trend generally follows a decreasing $\mathrm{R}_{\mathrm{A} / \mathrm{A}+\mathrm{B})}$, with perhaps some atypical healing for B1900 that reduces the final weight loss. Fig. $2 b$ shows the behaviour of the remaining alloys, ranging from -40 to $-330 \mathrm{mg} / \mathrm{cm}^{2}$. Again the trend with decreasing $\mathrm{R}_{\mathrm{A} / \mathrm{A}+\mathrm{B})}$ can be seen. MarM200 is slightly out of sequence, perhaps because the high $12 \% \mathrm{~W}$ level most likely had a negative effect, but was not accounted for in $\mathrm{R}_{\mathrm{A} /(\mathrm{A}+\mathrm{B})}$. The IN 738 and IN 792 appear to follow the same curve until a break occurs at $115 \mathrm{~h}$. (It was noted that duplicate runs with these two alloys have produced reversed order of performance, when their results in Table 4 are compared to data in Fig. $2 b$.

Finally, there appears to be a general distinction between the curves in Fig. $2 a$, many of which are flat or concave up and fit in a range of $10 \mathrm{mg} / \mathrm{cm}^{2}$, compared to those in Fig. $2 b$, which are all concave down and require an abscissa covering $\sim 25 \times$ greater range. The curves in Fig. $2 b$ are more classical examples of cyclic model curves, where the weight change curve reaches a constant final negative slope. Those concave up curves in Fig. $2 a$ thus exhibit a form of self-healing, in which the initial rate of weight loss decreases to a milder rate 


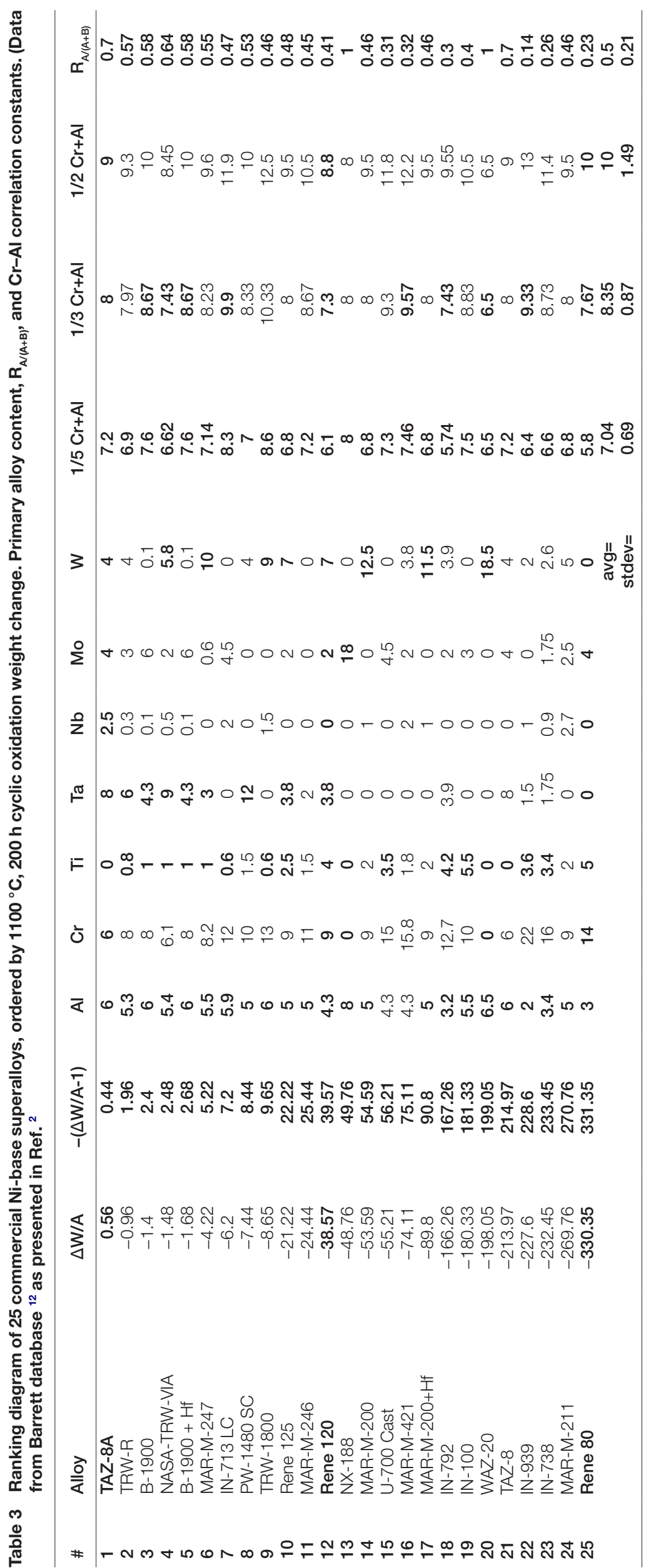


Table 4 Ranking diagram of 10 selected alloys from Table 3, spanning the range of performance

\begin{tabular}{|c|c|c|c|c|c|c|c|c|c|}
\hline \# & Alloy & $\mathrm{mg} / \mathrm{cm}^{2}$ & Al & $\mathrm{Cr}$ & $\mathrm{Ti}$ & $\mathrm{Ta}$ & $\mathrm{Nb}$ & Mo & W \\
\hline 1 & TAZ-8A & 0.56 & 6.0 & 6.0 & 0 & 8 & 2.5 & 4 & 4 \\
\hline 3 & B-1900 & -1.40 & 6.0 & 8.0 & 1 & 4.3 & 0.1 & 6 & 0.1 \\
\hline 4 & NASA-TRW-VIA & -1.48 & 5.4 & 6.1 & 1 & 9 & 0.5 & 2 & 5.8 \\
\hline 6 & MAR-M-247 & -4.22 & 5.5 & 8.2 & 1 & 3 & 0 & 0.6 & 10 \\
\hline 7 & IN-713 LC & -6.20 & 5.9 & 12.0 & 0.6 & 0 & 2 & 4.5 & 0 \\
\hline 12 & Rene 120 & -38.57 & 4.3 & 9.0 & 4 & 3.8 & 0 & 2 & 7 \\
\hline 14 & MAR-M-200 & -53.59 & 5.0 & 9.0 & 2 & 0 & 1 & 0 & 12.5 \\
\hline 18 & IN-792 & -166.26 & 3.2 & 12.7 & 4.2 & 3.9 & 0 & 2 & 3.9 \\
\hline 23 & IN-738 & -232.45 & 3.4 & 16.0 & 3.4 & 1.8 & 0.9 & 1.8 & 2.6 \\
\hline 25 & Rene 80 & -330.35 & 3.0 & 14.0 & 5 & 0 & 0 & 4 & 0 \\
\hline
\end{tabular}

(a)

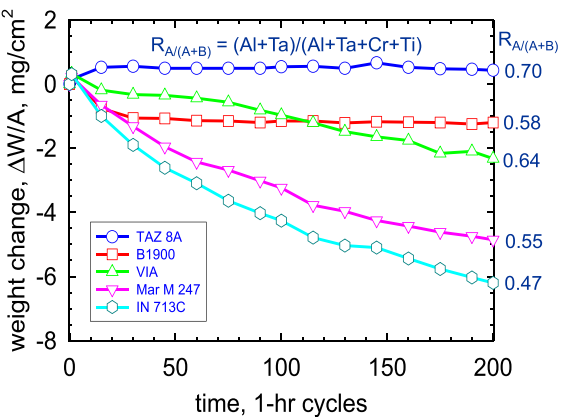

(b)

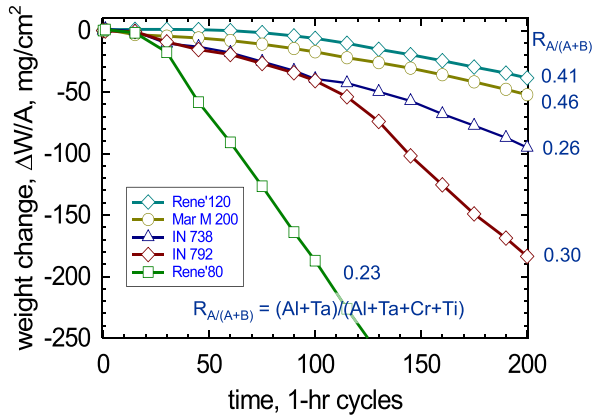

$21100{ }^{\circ} \mathrm{C}$ cyclic oxidation of the 10 representative superalloys from Table 3 . (a) Higher $R_{A /(A+B)}$ alloys losing less than 10 mg/ $\mathrm{cm}^{2}$ in $200 \mathrm{~h}$. (b) Lower $R_{\mathrm{A} /(\mathrm{A}+\mathrm{B})}$ alloys losing more than $30 \mathrm{mg} / \mathrm{cm}^{2}$ in $200 \mathrm{~h}$

of attack. It can be speculated that rapid initial weight loss is influenced by Ni-rich transient scales that are eventually replaced by a continuous, healing underlayer of protective alumina.

Traditional cyclic oxidation models predict only a downward curvature and are fitted best when the initial weight gain portion is clearly featured in the weight change curve. ${ }^{13}$ But in Fig. 2, most curves become negative very early and preclude a full modelling process, by either the (paralinear) attack parameter, based on parabolic growth and superimposed linear loss or cyclic modelling techniques. In any event, the final $200 \mathrm{~h}$ weight change appears to be a reasonable, well-behaved figure of merit for overall degree of cyclic oxidation attack. Ideally, the final slope is a more precise indication of total degradation, but, like fitted model curves, is one step removed from more easily identified weight change data. Since most curves did not exhibit significant degradation during the initial weight gain interval, the final weight change was deemed suitable as a distinguishing parameter for this data-set.

\section{Simple transform and graphical summary displays}

In order to present this information graphically, the weight change was converted to a simple transform, Z1, according to:

$$
Z 1=-(\Delta W / A-1)
$$

This has the attribute of converting all the weight change to a negative value, then changing the sign to positive. Since the weight change is only offset by $1 \mathrm{mg} / \mathrm{cm}^{2}$, it is essentially just the absolute value of large weight losses. This allows presentation of the data as a semi-log scatter diagram, where $\log \mathrm{Z} 1$ encompasses many orders of magnitude of weight change variability in a single plot. So, for example, all the alloy weight change data is shown as a function of Al content

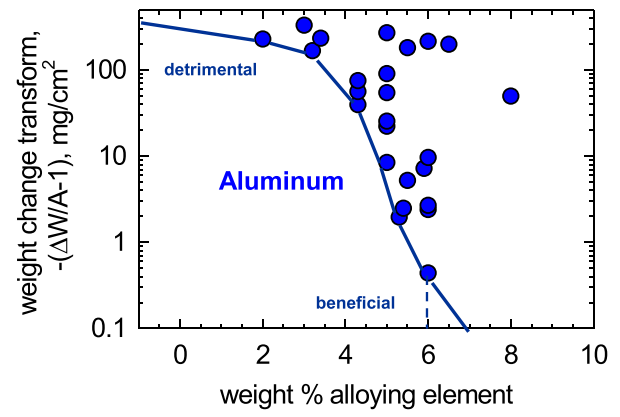

3 Scatter plot of $\mathrm{Z1}, 1100{ }^{\circ} \mathrm{C}, 200 \mathrm{~h}$ weight change transform, showing strong reductions in the lower bound with Al content

in Fig. 3, revealing a large scatter pattern, but bounded by the lower line indicating the best possible behaviour. The variation for any particular $\mathrm{Al}$ content is very large, yet the trend of the lower Z1 boundary line shows a steep decrease (over three orders of magnitude) as $\mathrm{Al}$ increases from 2 to $6 \%$. Conversely, Fig. 4 exhibits a steep increase in the $\mathrm{Z} 1$ lower bound (also three orders of magnitude) as Ti increases from 0 to $5.5 \%$. Here optimum performance is indicated for zero Ti. A weaker, but decreasing, trend with Ta content is shown in Fig. 5, where the better alloy performance improved by a factor of 20 over the range of $0-8 \%$ Ta.

A special problem arises for the case of $\mathrm{Cr}$ content because of its generally inverse correlation with $\mathrm{Al}$ content for these conventionally cast superalloys. The scatter diagram in Fig. 6 would suggest a significant increase in oxidative attack as $\mathrm{Cr}$ increases from $6-22 \%$. This is counter to conventional understanding whereby $\mathrm{Cr}$ is typically added to improve oxidation behaviour. This improvement results by either allowing $\mathrm{Al}_{2} \mathrm{O}_{3}$ formation at lower $\mathrm{Al}$ levels or to form protective $\mathrm{Cr}_{2} \mathrm{O}_{3}$ 


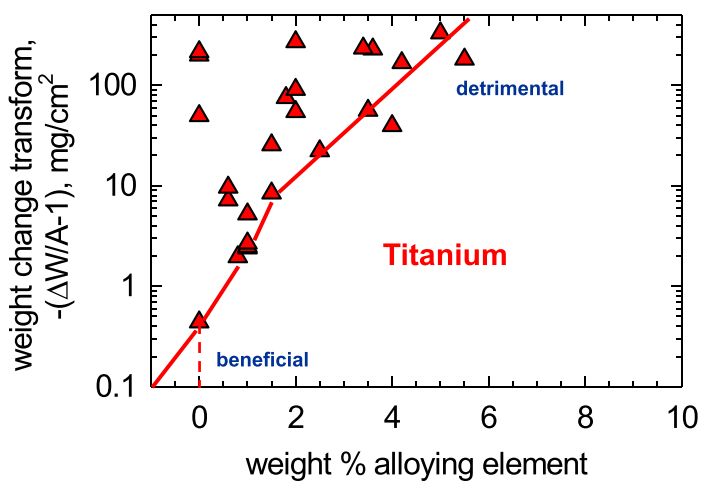

4 Scatter plot of $\mathrm{Z1}, 1100{ }^{\circ} \mathrm{C}, 200 \mathrm{~h}$ weight change transform, showing a large increase in the lower bound with Ti content

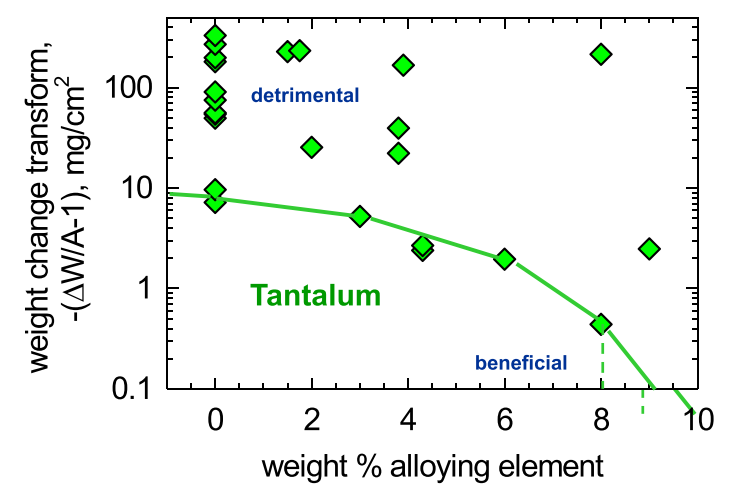

5 Scatter plot of $\mathrm{Z1}, 1100{ }^{\circ} \mathrm{C}, 200 \mathrm{~h}$ weight change transform, showing moderate reduction in the lower bound with Ta content

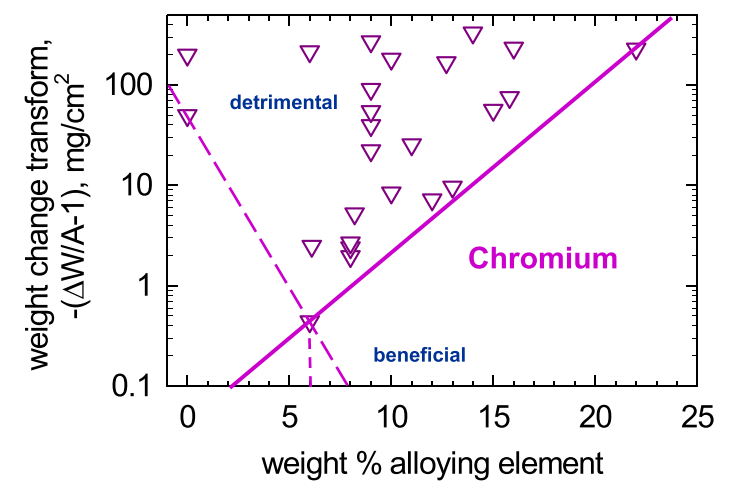

6 Scatter plot of $\mathrm{Z1}, 1100{ }^{\circ} \mathrm{C}, 200 \mathrm{~h}$ weight change transform, showing apparent increase in the lower bound with Cr content

scales at very high $\mathrm{Cr}$ levels. This apparent contradiction is resolved by recognising that in these many older superalloys, $\mathrm{Cr}$ content had been inversely related to $\mathrm{Al}$ content. This compositional relation is shown in Fig. 7, where, on average, increasing $\mathrm{Cr}$ content also implies decreasing $\mathrm{Al}$ content. Given the strong effect of $\mathrm{Al}$ on oxidation behaviour, one then obtains that the alloys with increasing $\mathrm{Cr}$ are associated with a detriment in oxidation behaviour. The inverse $\mathrm{Cr}-\mathrm{Al}$ correlation of this alloy set was quantified by linear regression, yielding:

$$
\mathrm{Al}+0.22 \mathrm{Cr}=7.25
$$

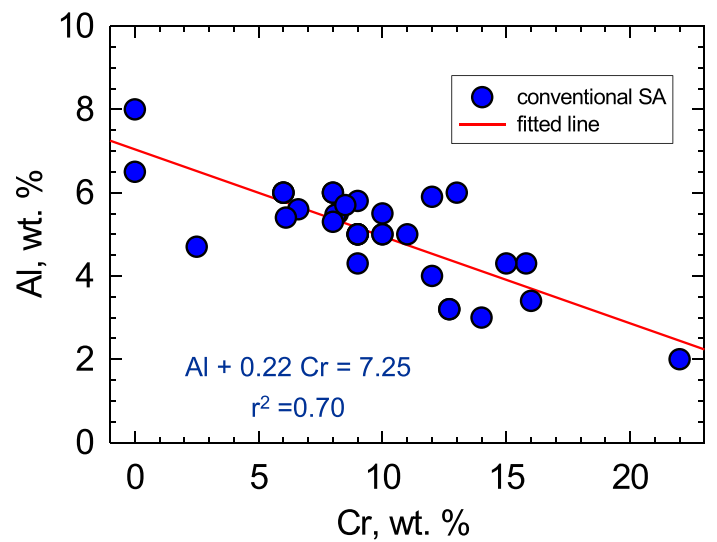

7 Inverse correlation of $\mathrm{Cr}$ and $\mathrm{Al}$ contents for $25 \mathrm{Ni}$-base superalloys

$$
r^{2}=0.70
$$

Given the scatter, it is reasonable to describe this correlation by the simple approximation that $1 / 5 \mathrm{Cr}+\mathrm{Al}=7$. This correlation constant is presented in the last column of Table 3 , with the average value of 7.0, varying from 5.8 to 8.3 . Previous overviews have presented similar approximations such as $1 / 2 \mathrm{Cr}+\mathrm{Al}=10,{ }^{1,2}$ with some utility for $1 / 3 \mathrm{Cr}+\mathrm{Al}=8$ as well. This correlation insures that this data-set cannot reveal a truly independent $\mathrm{Cr}$ effect. That is not to say that $\mathrm{Cr}$ cannot play a positive role. When decoupled from $\mathrm{Al}$, as in the statistical alloy design studies of Barrett, ${ }^{14,15}$ benefits due to increasing $\mathrm{Cr}$ at high $\mathrm{Al}$ have been identified more clearly. ${ }^{2}$

\section{Multiple linear regression model}

The lower boundary lines in Figs. 3-5 provide an instructive first look at compositional trends. However, the information in the rest of the scatter plot is unused. Here, more complex interaction terms would be operative. For this reason, an enlarged data-set from the CD database that accompanies the Barrett work ${ }^{10-12}$ was employed, using the open source statistical language and environment, R [www.r-project.org]. A total of 110 separate tests on 25 alloys (with 11 slight composition modifications) were the input data. A new transform, $\mathrm{Z} 4$, was used to accommodate tests showing a weight gain above $3 \mathrm{mg} / \mathrm{cm}^{2}$,

where:

$$
Z 4=-(\Delta W / A-4)
$$

and:

$$
\ln Z 4=\beta_{0}+\sum_{i} \beta_{i} x_{i}+\sum_{i j} \beta_{i j} x_{i} x_{j}
$$

where: $\mathrm{i}$ and $\mathrm{j}$ are tags for elements and $\mathrm{x}$ is composition in wt. $\%$.

Accordingly, the following equation was derived:

$$
\begin{aligned}
\ln (Z 4)= & \beta_{0}+\beta_{1} \cdot \mathrm{Al}+\beta_{2} \cdot \mathrm{Ti}+\beta_{3} \cdot \mathrm{Ta} \cdot \mathrm{Mo} \\
& +\beta_{4} \cdot \mathrm{Ti} \cdot \mathrm{Nb}+\beta_{5} \cdot \mathrm{Ta} \cdot \mathrm{Hf}+\beta_{6} \cdot C \cdot W \\
& +\beta_{7} \cdot \mathrm{Nb} \cdot W+\beta_{8} \cdot \mathrm{Al} \cdot \mathrm{Mo} \\
& +\beta_{9} \cdot \mathrm{C} \cdot \mathrm{Co}+\beta_{10} \cdot \mathrm{Mo} \cdot \mathrm{Hf}
\end{aligned}
$$

The results, complete with supporting statistical significance tests are listed in the Appendix, for the ln Z4 version of the regression fit parameters, Table A1. Sorting by sign 
Table 5 Regression equation terms, sorted by sign and magnitude, relating log $Z 41100{ }^{\circ} \mathrm{C}$ cyclic oxidation transform to composition, where $Z 4=-\left(\Delta W / A_{200 h r}-4\right)$

\begin{tabular}{lccc}
\hline Beneficial & & \multicolumn{2}{c}{ Detrimental } \\
\hline$\beta_{\mathrm{ij}}$ & $\mathrm{X}_{\mathrm{ij}}$ & $\beta_{\mathrm{ij}}$ & $\mathrm{X}_{\mathrm{ij}}$ \\
\hline-0.263 & $\mathrm{Al}$ & 0.011 & $\mathrm{Mo} \cdot \mathrm{Hf}$ \\
-0.138 & $\mathrm{Nb} \cdot \mathrm{W}$ & 0.12 & $\mathrm{C} \cdot \mathrm{W}$ \\
-0.067 & $\mathrm{Ta} \cdot \mathrm{Mo}$ & 0.134 & $\mathrm{Al} \cdot \mathrm{Mo}$ \\
-0.028 & $\mathrm{Ta} \cdot \mathrm{Hf}$ & 0.146 & $\mathrm{Ti}$ \\
-0.014 & $\mathrm{C} \cdot \mathrm{Co}$ & 0.52 & $\mathrm{Ti} \cdot \mathrm{Nb}$ \\
& & 2.218 & $\left(\beta_{0}\right.$, Intercept) \\
\hline
\end{tabular}

Note: $\log _{10} Z 4=\beta_{\circ}+\sum_{i} \beta_{i}\left(X_{i}\right)+\sum_{i j} \beta_{i j}\left(X_{i} X_{j}\right) ; r^{2}=0.84$

and magnitude, one obtains the beneficial and detrimental terms in the $\log _{10} \mathrm{Z} 4$ converted version, Table 5. It should be emphasised that this equation has been optimised to address the composition space presented by the 25 alloys in the dataset. A broader set, including experimental alloys where the $\mathrm{Cr}$ and $\mathrm{Al}$ contents are de-coupled, would likely result in different terms, while still faithfully representing the combined data-set.

Note that the coefficient of determination $\left(R^{2}\right)$ is similar to that determined by Barrett. ${ }^{2}$ Barrett used a larger data-set with testing performed at more than one temperature. Barrett's equation had 15 terms, two of which compensated for temperature, and two of which included the highly correlated variables of $\mathrm{Al}$ and $\mathrm{Cr}$.

Diagnostics of this fit show that the residuals are fairly well behaved with no obvious outliers. Some of the terms in this model are shared with Barrett's model: $\mathrm{Al}, \mathrm{Ti}, \mathrm{Ti} \cdot \mathrm{Nb}$ and Al-Mo. (Note that TAZ 8 data with $2 \% \mathrm{~V}$ were omitted from the analysis since the negative effect was severe compared to TAZ 8A without V. IN100 tests with $1 \% \mathrm{~V}$, which again caused severe effects, were also omitted because of these two limited alloys containing V.)

\section{Projected behaviours and graphical illustrations}

\section{Base alloys, $Z_{4}$ transform and term sensitivity}

The transform regression equation provides a better tool for projecting oxidation weight change. The predicted values of the Z4 transform are plotted against actual values for an individual test in the log-log graph of Fig. 8. Clustering about the predicted line appears reasonable, but with a fair degree of scatter. In some cases this scatter amounts to large values of actual weight change (log scale). However, it is noted that we are attempting to predict values over the wide range of $+3--300 \mathrm{mg} / \mathrm{cm}^{2}$ final weight change. Results for duplicate tests are shown in Figure A1.

In applying this equation, the many interaction terms somewhat obscure individual elemental effects, making an assessment by inspection difficult. Consequently, a number of graphical approaches are used to illustrate selected compositional effects. The basic strategy is to select various base alloys and vary one element at a time, then present the associated Z4 transform or weight change response. In order to visualise optimal performance trends, base compositions were chosen in the range of the top performing group of alloys, Table 3 . First, a value of $6 \mathrm{wt} . \%$ each was assigned to all the major alloying elements $\mathrm{Al}, \mathrm{Co}, \mathrm{Cr}$ and $\mathrm{Ta}$, i.e. base $(6,6,6,6)$, for the sake of simplicity. As will be seen below, these elements provide positive or neutral effects. To explore base alloy sensitivity to the minor elements, $\mathrm{Ti}, \mathrm{Nb}, \mathrm{Mo}$ and

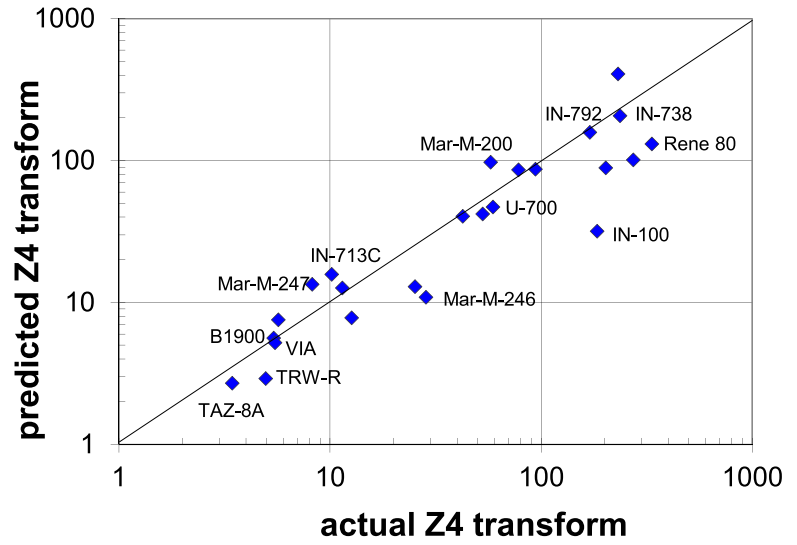

8 Z4 parameter predicted by multiple linear regression vs. actual $Z 4$, where $Z 4=-(\Delta W / A-4)$ for 25 superalloys oxidised at $1100^{\circ} \mathrm{C}$ for $200 \mathrm{~h}$

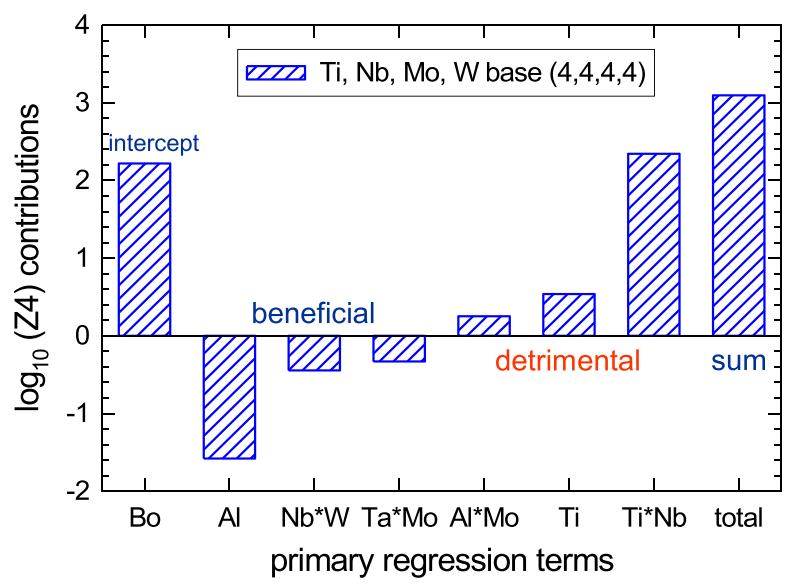

9 Term by term contributions to predicted $\log _{10} \mathbf{Z 4}$ for various ( $\mathrm{Ti}, \mathrm{Nb}, \mathrm{Mo}, \mathrm{W}$ ) base alloys, all having $\mathrm{Al}, \mathrm{Co}, \mathrm{Cr}$, $\mathrm{Ta}=6$ wt. $\%\left(1100{ }^{\circ} \mathrm{C}, 200 \mathrm{~h}\right)$

W were fixed at identical base ${ }_{2}$ values $(0,1,2$ or 4 wt.\%), again for the sake of simplicity. These values cover much of the compositional range for the alloys in Table 3. The Hf and $\mathrm{C}$ contents were fixed at typical nominal values of 0.2 and 0.1 , respectively.

The term by term results for $\log _{10} \mathrm{Z} 4$ (Equation 1) are summarised in Fig. 9 for the six terms providing the largest effect. (For clarity and emphasis, only the results for the high $4 \%$ base ${ }_{2}$ level of $\mathrm{Ti}, \mathrm{Nb}, \mathrm{Mo}$ and $\mathrm{W}$ is provided). The $\mathrm{Al}$ term clearly provides the most powerful beneficial effect in reducing the value of $\log _{10} \mathrm{Z} 4$, followed by $\mathrm{Nb} \cdot \mathrm{W}$ and $\mathrm{Ta} \cdot \mathrm{Mo}$, (then $\mathrm{Ta} \cdot \mathrm{Hf}$, and $\mathrm{C} \cdot \mathrm{Co}$, not shown). On the detrimental side, 


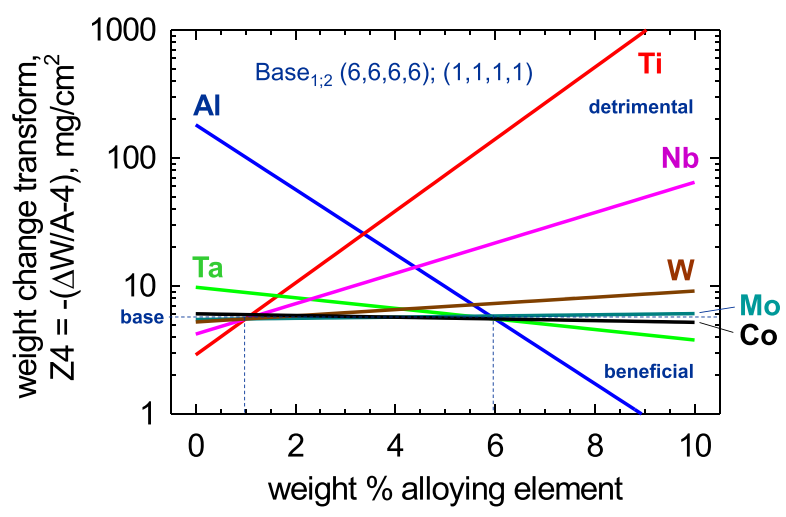

10 Linear semi-log plots of the individual elemental effects on predicted Z4. Compared to a base alloy of $(6,6,6,6) \mathrm{Al}$, $\mathrm{Co}, \mathrm{Cr}$, Ta and $(1,1,1,1) \mathrm{Ti}, \mathrm{Nb}, \mathrm{Mo}$, W, with $0.2 \mathrm{Hf}$ and 0.1 $\mathrm{C}$ (wt.\%) $\left(1100^{\circ} \mathrm{C}, 200 \mathrm{~h}\right)$

the $\mathrm{Ti} \cdot \mathrm{Nb}$ term was the most powerful at these high levels, even surpassing the beneficial effect of Al, followed by Ti, and successively decreasing contributions of $\mathrm{Al} \cdot \mathrm{Mo}$, (then $\mathrm{Co} \cdot \mathrm{W}$, and Mo Hf, not shown). The total value (sum) indicates the projected performance and includes the intercept value of 2.218 for $\beta_{0}$ ). Restated, the associated scales and regression fit terms reflect beneficial, protective slow growing vs. detrimental, non-protective, fast growing. In the extremes, the former result in minimal weight loss (or a small gain), the latter result in massive losses.

Some terms, such as $\mathrm{Nb} \cdot \mathrm{W}$ and $\mathrm{Al} \cdot \mathrm{Mo}$, appear to contribute in a counterintuitive direction. However, these have small coefficients and serve to buffer the extreme effect of other opposing terms containing $\mathrm{Nb}$ and $\mathrm{Al}$ with larger coefficients. The effect of incrementally ramping the minor elements from 1, 2 and $4 \%$ is to successively double the terms containing $\mathrm{Ti}, \mathrm{Nb}$, Mo or $\mathrm{W}$ (or quadruple the contribution if two of these elements are contained in the term). For example, the base ${ }_{2}$ levels of $(1,1,1,1)$, would produce noticeably reduced contributions for their terms in Fig. 9, but are not shown for clarity.

One might thus conclude that $\mathrm{Ti}, \mathrm{Nb}$, Mo or $\mathrm{W}$ should all be zero to investigate elemental sensitivities near an optimum value. However, this would eliminate 7 of the 10 terms in Equation 6 and provide no insights regarding real superalloy compositions. Since most superalloys will contain at least some of these minor elements, a base alloy was arbitrarily chosen with $\mathrm{Ti}, \mathrm{Nb}, \mathrm{Mo}$ and $\mathrm{W}$ contents equal to 1.0 , i.e. base b $_{2}=(1,1,1,1)$, again for simplicity and in a range for many of the better performing alloys shown in Table 3.

A semi-log plot of Z4 against wt.\%, Fig. 10, most completely represents the sensitivity exercise over the entire $0-10 \%$ input range. Starting from the two $(6,6,6,6)$ base $_{1}$ and $(1,1,1,1)$ base $_{2}$ levels, shown by the dashed lines, the major and minor elements are varied one at a time. By inspection of Equation 6, all responses are linear. We see that the severity of cyclic oxidation is reduced primarily by increasing $\mathrm{Al}$ content, followed by a secondary effect for Ta. Conversely, the severity is increased most powerfully by Ti, followed by $\mathrm{Nb}$, then $\mathrm{W}$. Negligible effects are predicted for Co and Mo. The experimental results range from -300 to $+3 \mathrm{mg} / \mathrm{cm}^{2}$, and most of the compositional space examined is seen to be covered by this one plot.

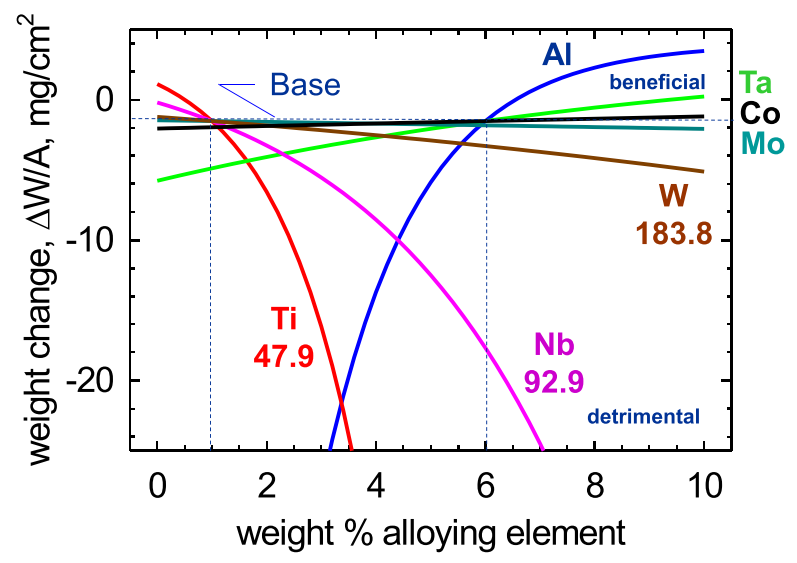

11 Cyclic oxidation weight change as a function of composition. Predicted from multiple linear regression for elemental variations from a standard base alloy $\left(1100{ }^{\circ} \mathrm{C}, 200 \mathrm{~h}\right)$

\section{Weight change illustrations}

Single element variations

Nevertheless, the transform $\log _{10} \mathrm{Z} 4=\log _{10}\left[-\left(\Delta \mathrm{W} / \mathrm{A}_{200}-4\right)\right]$ is somewhat removed from the more familiar quantity of weight change. Accordingly, Fig. 11 directly presents the projected weight change on a linear scale as a function of elemental variations from a specified base alloy: $6(\mathrm{Al}, \mathrm{Co}, \mathrm{Cr}, \mathrm{Ta})-1 \%$ (Ti, Nb, Mo, W) wt.\% covering the preferred compositional space. The weight change predicted for this starting base alloy is approximately $-1.5 \mathrm{mg} / \mathrm{cm}^{2}$ (note the dashed lines). The strong beneficial effect of $\mathrm{Al}$, which rises from a low of $-180 \mathrm{mg} / \mathrm{cm}^{2}$ at $0 \mathrm{Al}$ to relatively small positive values above $6.6 \%$, is clear. (However, these positive predicted values may become somewhat unrealistic for protective alumina scales $\left(>2 \mathrm{mg} / \mathrm{cm}^{2}\right)$ because of the nature of fitting a wide response field with a minimal number of terms). It is more significant that the response shows a rapid improvement from negative to positive followed by a levelling off.

Conversely, the Ti response curve becomes increasingly negative above just $0.5 \%$, reaching nearly $-100 \mathrm{mg} / \mathrm{cm}^{2}$ at the top end of its range for the alloys analysed, i.e. $\sim 5.5 \%$. $\mathrm{Nb}$, and then $\mathrm{W}$, also present significant detrimental trends, though decreasing in severity. Ta exhibits a moderate beneficial effect, producing a positive weight change at $\sim 6 \%$. This is compared to a minor detrimental effect of Mo and negligible effect of Co.

The projected weight change is now presented as a function of atomic per cent in Fig. 12. This helps provide a more atom specific perspective of each elemental effect. Values were generated as before, corresponding to individual elemental variations from the base composition, now converted to Ni-5.8Co-12.7Al-6.6Cr-1.9Ta-1.2Ti-0.6Nb-0.6Mo-0.3W$0.065 \mathrm{Hf}-0.48 \mathrm{C}$ at. $\%$. The symbols on each curve represent the starting base levels of those elements, all fixed as another element was varied one at a time. It is immediately seen that $\mathrm{Al}$ levels $>13$ at. $\%$ are needed to achieve optimum behaviour. The negative effects of $\mathrm{Ti}$ and $\mathrm{Nb}$ now appear to be nearly equivalent on an atom $\%$ basis, while $\mathrm{W}$ appears only half as detrimental. The positive effect of Ta is nearly a mirror image of the negative effect of $\mathrm{W}$, but extends only to about 3.3 at. $\%$ for the range studied (10 wt.\%). Again, Mo and Co exhibit small or negligible effects. 


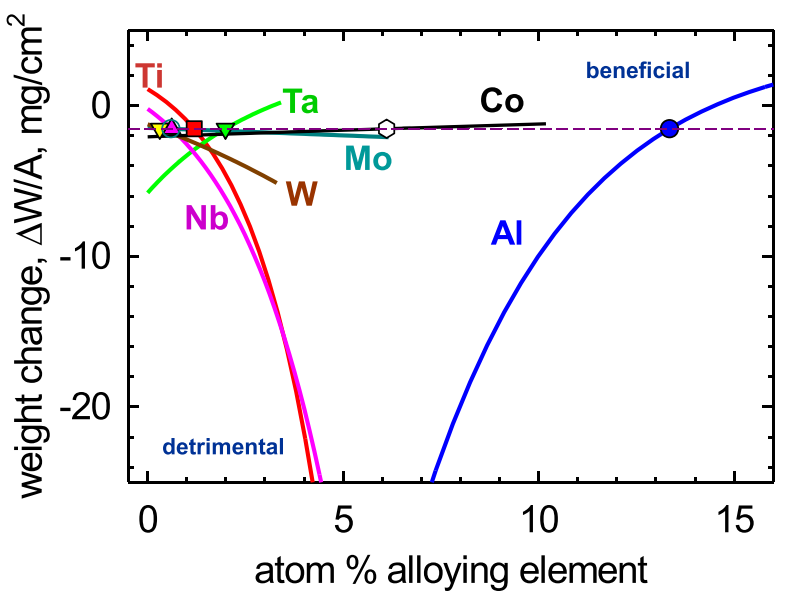

12 Predicted cyclic oxidation weight change as a function of composition in atomic $\%\left(1100{ }^{\circ} \mathrm{C}, 200 \mathrm{~h}\right)$

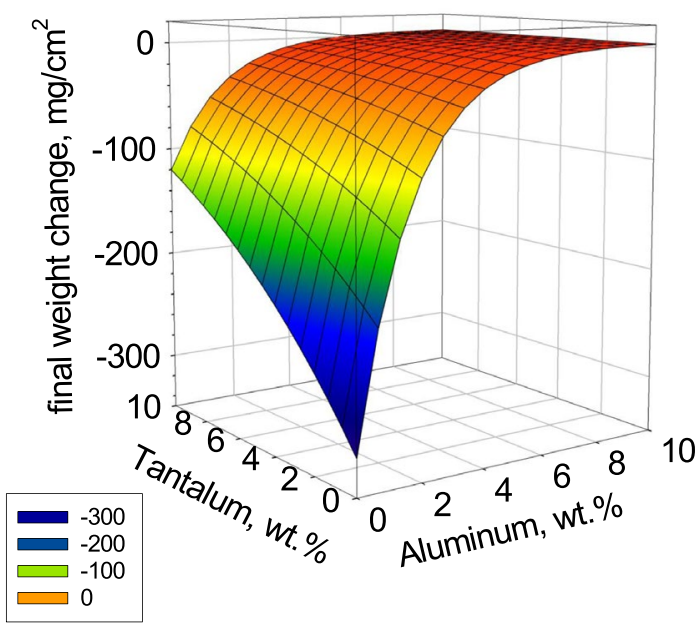

13 3-D view of additive beneficial effects of $\mathrm{Al}$ and Ta on predicted weight change. $6(\mathrm{Co}, \mathrm{Cr})$ and $1(\mathrm{Ti}, \mathrm{Nb}, \mathrm{Mo}, \mathrm{W})$ base alloy $\left(1100^{\circ} \mathrm{C}, 200 \mathrm{~h}\right)$

Multi-element variations; response surfaces on 3-D plots Finally, we examine response surfaces generated by two variables, fixing the remainder as before. Fig. 13 shows projected final weight change for the primary beneficial elements, $\mathrm{Al}$ and Ta, fixing a base level of $1 \mathrm{wt} . \%$ for $\mathrm{Ti}, \mathrm{Nb}$, Mo and $\mathrm{W}$ as before. Basically a monotonic, exponential sheet is obtained, showing the considerable improvements and near asymptotic behaviour by increasing $\mathrm{Al}$ content, even at $0 \% \mathrm{Ta}$. On this linear scale, the additive negative effect of having both low $\mathrm{Al}$ and Ta are seen as quite dramatic. The superimposed response surfaces for various ( $\mathrm{Ti}$, $\mathrm{Nb}, \mathrm{Mo}, \mathrm{W})$ base $_{2}$ levels are shown in Fig. 14. An increase in the base ${ }_{2}$ level to (2222) exhibits even more dramatic effects at low $\mathrm{Al}$ and $\mathrm{Ta}$, to the point that $1000 \mathrm{mg} / \mathrm{cm}^{2}$ weight loss is projected. Indeed, the surface obtained for the higher (4444) base ${ }_{2}$ level is so steep that it extends well beyond the scale of this plot. The general implication is that higher levels of $\mathrm{Ti}$ and refractory elements degrade performance significantly. However, it is recognised that no degree of accuracy for predicting beyond the experimental space (i.e. past $-330 \mathrm{mg} / \mathrm{cm}^{2}$ weight loss) can be assured by the regression analysis.

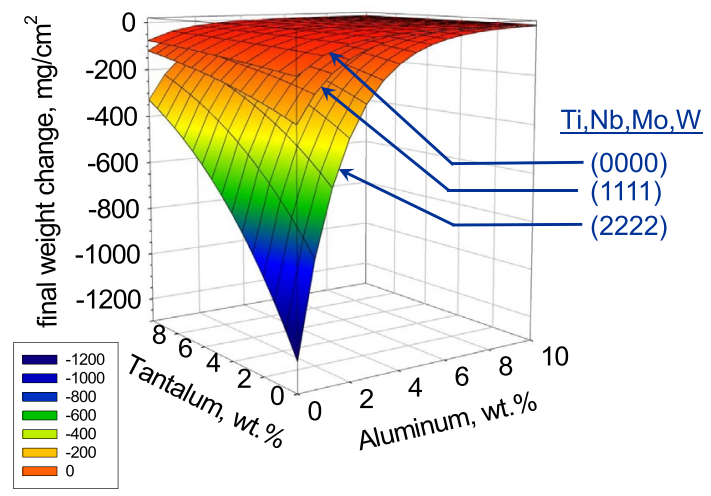

14 3-D view of detrimental (Ti,Nb,Mo,W) base ${ }_{2}$ level effects on the $\mathrm{Al}$, Ta response surfaces $\left(1100^{\circ} \mathrm{C}, 200 \mathrm{~h}\right)$

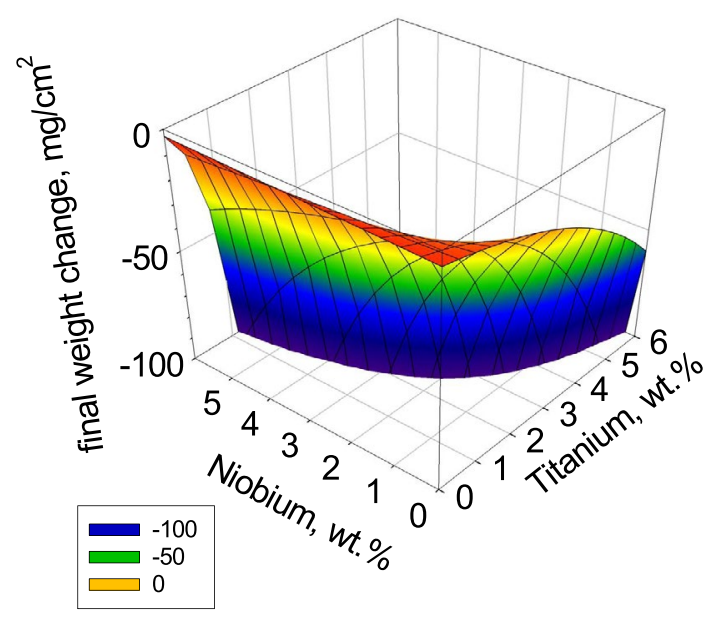

15 3-D view of the synergistic detrimental effect of Ti and $\mathrm{Nb}$ on predicted weight change. 6 (Al,Co, $\mathrm{Cr}, \mathrm{Ta})$ and 1 $(\mathrm{Mo}, \mathrm{W})$ base alloy $\left(1100^{\circ} \mathrm{C}, 200 \mathrm{~h}\right)$

Correspondingly, an opposing final weight change response surface for varying the primary detrimental elements, $\mathrm{Ti}$ and $\mathrm{Nb}$, is shown in Fig. $15(\mathrm{Mo}, \mathrm{W}=1)$. For $\mathrm{Al}$ and $\mathrm{Ta}=6$, the effect of increasing $\mathrm{Ti}$ is strong compared to $\mathrm{Nb}$, but the synergistic effect of both elements is stronger. This can be discerned by examining the contour lines at constant $\mathrm{Ti}$ as a function of $\mathrm{Nb}$. At the lowest $\mathrm{Ti}$, there is little effect of $\mathrm{Nb}$, while, at high $\mathrm{Ti}$, the detrimental effect of $\mathrm{Nb}$ is extremely negative. And the contour lines for constant $\mathrm{Nb}$ show a strong negative function of $\mathrm{Ti}$ at low $\mathrm{Nb}$, becoming more extreme at high $\mathrm{Nb}$. These features derive from the large coefficient of the Ti-Nb term in Equation 6, Table 5. Finally, the effect of Al level on the Ti-Nb response surface is displayed in Fig. 16. While all the same Ti-Nb effects follow the same form, it can now be seen that the negative effects are minimised at high $\mathrm{Al}$ levels for moderate $\mathrm{Ti}$ and $\mathrm{Nb}$. Conversely, behaviour is projected to be universally poor as $\mathrm{Al}$ decreases far below $6 \% \mathrm{Al}$, even at low $\mathrm{Ti}$ and $\mathrm{Nb}$ contents. It is believed that much of the projected behaviours are consistent with the initial assessment of scale phases in Table 2 and Fig. 1, which indicated a predominance of $\alpha-\mathrm{Al}_{2} \mathrm{O}_{3}, \mathrm{Ni}(\mathrm{Al}, \mathrm{Cr})_{2} \mathrm{O}_{4}$ spinel and $\mathrm{NiTa}_{2} \mathrm{O}_{6}$ tri-rutile for the alloys exhibiting the least weight change and $\alpha-\mathrm{Cr}_{2} \mathrm{O}_{3}, \mathrm{NiCr}_{2} \mathrm{O}_{4}$ spinel, $\mathrm{NiO}$ and $\mathrm{NiTiO}_{3}$ for the higher weight changes. Given the prominence of the $\mathrm{Ti}-\mathrm{Nb}$ 


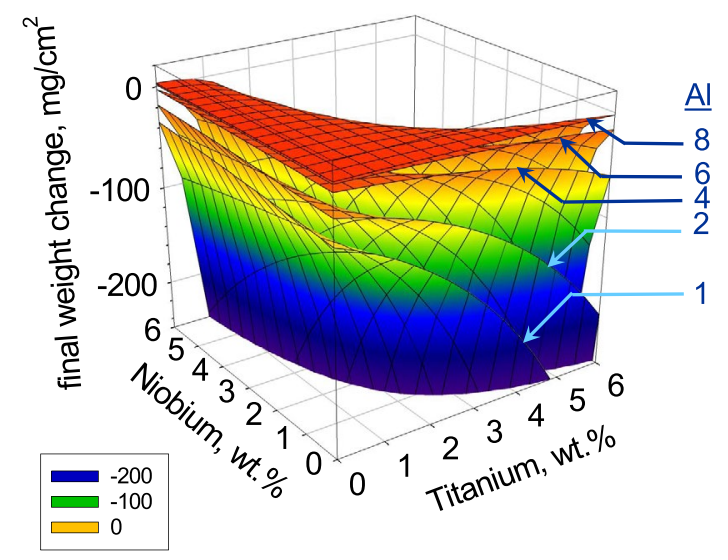

16 3-D view of the beneficial effects of $\mathrm{Al}$ on the $\mathrm{Ti}, \mathrm{Nb}$ response surfaces $\left(1100^{\circ} \mathrm{C}, 200 \mathrm{~h}\right)$

interaction term, a negative effect of some scale phase related to Ti-Nb oxide might be expected, such as $\mathrm{TiNbO}_{4}$.

An attempt was made to apply Equation 6 to various single crystal superalloys, while ignoring any $\mathrm{Ru}$ or $\mathrm{Re}$ effects which are not included in the model. It was found that for well-behaved Rene'N5, Rene'N6 and PWA 1484 alloys, the projection was within $1-2 \mathrm{mg} / \mathrm{cm}^{2}$ of the actual weight change. For example, $0.1 \mathrm{mg} / \mathrm{cm}^{2}$ was predicted compared to $0.6 \mathrm{mg} / \mathrm{cm}^{2}$ actually measured for Rene' $\mathrm{N} 5$. This is remarkable agreement for an equation designed to cover behaviour from -330 to $+3 \mathrm{mg} / \mathrm{cm}^{2}$. However, the regression model seriously over-predicted weight loss for Rene' N4 (-104 vs. $\left.-1 \mathrm{mg} / \mathrm{cm}^{2}\right)$ because of its high Ti content $(4.2 \%)$ and lower $\mathrm{Al}$ content $(3.7 \%)$. Various studies have sought to co-optimise the oxidation resistance of single crystal properties, with one aspect generally serving as the primary focus. A high $\mathrm{Cr}$, but lower $\mathrm{Al}$, single crystal alloy was developed (SCA425/STAL-15) to promote more $\mathrm{Cr}_{2} \mathrm{O}_{3}$ enriched scales for corrosion resistance in stationary gas turbines and helium reactors. ${ }^{16,17}$ The optimal composition was identified as Ni-5.8Co-4.55Al-15.5Cr-8.0 Ta-1.0Mo4.0W-2.3Re-0.5Si-200 ppm Ce, and fits reasonably well with the oxidation precepts outlined in this study. Additional studies co-optimised oxidation resistance with a focus on reducing density by replacing W with Mo. ${ }^{18,19}$ Here it was found that about $7 \mathrm{wt} . \%$ Mo could be tolerated in a balanced, high creep strength, nominally Ni-10Co-6.0Al-5.0Cr-6.2Ta-7.0Mo-3.0Re-0.2Hf-100 ppm Y, C alloy. The acceptability of moderately high Mo levels is consistent with the weak trends identified in Figs. 10-12. At another extreme, disk alloys (e.g. LSHR, ME3, Alloy 10, RR1000) are notably higher in $\mathrm{Cr}(12-15 \%)$, Ti (3.5-4\%) and $\mathrm{Nb}(1.4 \%)$, while being lower in $\mathrm{Al}(3.0-3.5 \%)$. According to the prior analysis, this will be sufficient to skew oxidation behaviour significantly towards non-protective $\mathrm{Ti}, \mathrm{Cr}$-rich rather than protective Al-rich external scales expected for single crystals. ${ }^{20,21}$ For example, Equation 6 predicts a weight loss of $\sim 270 \mathrm{mg} / \mathrm{cm}^{2}$ for LSHR compositions and implies much more severe oxidation than $\sim 1 \mathrm{mg} / \mathrm{cm}^{2}$ projected for single crystals. This provides another incentive for a hybrid disk concept proposing a bonded outer rim of single crystal elements. While single crystal behaviour and disk alloys are of great interest, more detailed analyses at this point would stretch beyond the scope of this database and the associated regressions.

\section{Summary and concluding remarks}

This study attempted to extract general compositional trends affecting the cyclic oxidation resistance of $25 \mathrm{Ni}$-base superalloys. The results of $1100^{\circ} \mathrm{C}, 200 \mathrm{~h}$ cyclic furnace tests from the Barrett database on cyclic oxidation was used as source material. Simple, transparent ranking diagrams (ordered tables) and scatter plots of a weight change transform (Z1) were constructed to produce a first-order indication of compositional effects. Both indicated that superior behaviour was exhibited by alloys containing over $5 \% \mathrm{Al}$ (and $\sim 6 \% \mathrm{Ta}$ ), but less than $1 \% \mathrm{Ti}$ (wt.\%). A preferred $\mathrm{Cr}$ level was difficult to target since $\mathrm{Cr}$ was strongly, but inversely, correlated with $\mathrm{Al}$ content, according to an average rule of thumb, whereby $1 / 5 \mathrm{Cr}+\mathrm{Al} \approx 7$. These trends further correlated with previous quantitative X-ray diffraction analyses of scale phases for four of these superalloys. Here the atom ratio of $(\mathrm{Al}+\mathrm{Ta}) /$ $(\mathrm{Al}+\mathrm{Ta}+\mathrm{Cr}+\mathrm{Ti})$ in the alloy was highly correlated with the ratio of beneficial scale phases $\left\{\alpha-\mathrm{Al}_{2} \mathrm{O}_{3}, \mathrm{Ni}(\mathrm{Al}, \mathrm{Cr})_{2} \mathrm{O}_{4}\right.$, plus $\left.\mathrm{NiTa}_{2} \mathrm{O}_{6}\right\}$ to detrimental ones $\left\{\alpha-\mathrm{Cr}_{2} \mathrm{O}_{3}, \mathrm{NiCr}_{2} \mathrm{O}_{4}, \mathrm{NiO}\right.$, plus $\left.\mathrm{NiTiO}_{3}\right\}$, as measured by weight loss in cyclic oxidation tests.

A more quantitative predictive tool was developed by multiple linear regression of another similar weight change transform (Z4). The variation in predicted weight change was studied for compositions clustering around an optimum range for typical alloys having $\mathrm{Al}, \mathrm{Co}, \mathrm{Cr}, \mathrm{Ta}=6 \%$ and $\mathrm{Ti}$, $\mathrm{Nb}, \mathrm{Mo}, \mathrm{W}=1 \%$. Again, the $\mathrm{Cr}$ term could not be isolated because of its strong correlation with $\mathrm{Al}$ content. A bar chart, 2-D and 3-D graphs were employed to illustrate the major effects of seven primary superalloy elements. These broad trends and specific predictions aid in understanding the severity of cyclic oxidation responses and can be used to help guide improvements for complex alloys within this range of compositions. Specifically, it is concluded that the degree of oxidation attack, as indicated by the final cyclic oxidation weight change, is influenced accordingly by the following composition factors:

1. Al strongly and Ta moderately reduces oxidative degradation.

2. Ti is especially detrimental to oxidative performance and $\mathrm{Nb}$ can be just as harmful on an atom basis.

3. There is a strong negative synergy between $\mathrm{Ti}$ and $\mathrm{Nb}$ at the higher levels, resulting in severe attack.

4. $\mathrm{W}$ is only moderately detrimental, while negligible effects on oxidative performance are indicated for Mo and Co.

5. Predicted compositional effects are generally consistent with prior studies of beneficial and detrimental scale phases associated with minimal and excessive oxidation attack, respectively.

While this preliminary exercise provided basic insights available from this particular data-set for conventional cast superalloys, it is recognised that a more robust treatment may include the effect of temperature from this database and data for single crystals, disk or experimental alloys from other studies.

\section{Acknowledgements}

The authors are grateful to Dr. J.A. Auping for providing a user-friendly interface with which to search and select data from the 3000 tests in the Barrett database. C.A. Barrett is acknowledged for his extensive accumulation and cataloguing of superalloy cyclic oxidation tests. 


\section{Disclosure statement}

No potential conflict of interest was reported by the authors.

\section{Funding}

This work was funded by the NASA Fundamental Aeronautics Program.

\section{ORCID}

James L. Smialek (D) http://orcid.org/0000-0003-4310-5569

\section{References}

1. J. L. Smialek and G. H. Meier: Chapter 11, "High temperature oxidation," in Superalloys II, C. T. Sims, N. S. Stoloff, W. C. Hagel, eds., 1987, 293-326. Wiley, New York, NY.

2. J. L. Smialek, C. A. Barrett and J. C. Schaeffer: 'Design for oxidation', in Design for properties, ASM Handbook, 1997, 20, 589-602, ASM, Materials Park, $\mathrm{OH}$.

3. J. L. Smialek, J. A. Nesbitt, C. A. Barrett and C. E. Lowell: 'Cyclic oxidation testing and modelling: a NASA Lewis perspective," in Cyclic oxidation of high temperature materials, M. Schutze and W. J. Quadakkers, eds., 1999, 148-168, European Federation of Corrosion, Institute of Materials, London (Also NASA TM 2000-209769).

4. C. S. Giggins and F. S. Pettit: 'Oxidation of $\mathrm{Ni}-\mathrm{Cr}-\mathrm{Al}$ alloys between $1000^{\circ} \mathrm{C}$ and $1200^{\circ} \mathrm{C}, '$ J. Electrochem. Soc., 1971, 118, 1782-1790.

5. C. A. Barrett and C. E. Lowell: 'Resistance of $\mathrm{Ni}-\mathrm{Cr}-\mathrm{Al}$ alloys to cyclic oxidation at $1100^{\circ} \mathrm{C}$ and $1200{ }^{\circ} \mathrm{C}$,' Oxid. Met., 1977, 11, 199-223.

6. C. A. Barrett, G. J. Santoro and C. E. Lowell: 'Isothermal and cyclic oxidation at $1000{ }^{\circ} \mathrm{C}$ and $1100{ }^{\circ} \mathrm{C}$ of four nickel-base alloys, NASATRW VIA, B-1900, 713C, 738X,' NASA TN D-7484, 1973. http://www. sti.nasa.gov/

7. R. G. Garlick and C. E. Lowell: 'Alloy composition effects on oxidation products of VIA, B-1900, 713C, and 738X - A high temperature diffractometer study,' NASA TM X-2796, June, 1973. http://www.sti. nasa.gov/

8. C. A. Barrett: 'A statistical analysis of elevated temperature gravimetric cyclic oxidation data of Ni- and Co-base superalloys based on an oxidation attack parameter,' NASA TM-105934, December, 1992. http://www.sti. nasa.gov/

9. C. E. Lowell, C. A. Barrett, R. W. Palmer, J. V. Auping and H. B. Probst: 'COSP: a computer model of cyclic oxidation', Oxid. Met., 1991, 36, 81-112.

10. C. A. Barrett, R. G. Garlick and C. E. Barrett: 'High temperature cyclic oxidation data, part 1,' NASA TM-83665, October, 1989. http://www. sti.nasa.gov/

11. C. A. Barrett and R. G. Garlick: 'High temperature cyclic oxidation data part 2,' NASA TM-101468, October, 1989. http://www.sti.nasa.gov/

12. C. A. Barrett: 'A high temperature cyclic oxidation data base for selected materials tested at NASA glenn research center,' NASA/TM-2003-212546, September, 2003. http://www.sti.nasa.gov/

13. J. L. Smialek and J. V. Auping: 'COSP for windows, "strategies for rapid analyses of cyclic oxidation behavior,' Oxid. Met., 2002, 57(5-6), 559581. (also NASA TP 2002-211108, February, 2002).

14. C. A. Barrett, R. V. Miner and D. R. Hull. 'The effects of Cr, Al, Ti, Mo, $\mathrm{W}, \mathrm{Ta}$, and $\mathrm{Cb}$ on the cyclic oxidation behavior of cast Ni-base superalloys at $1100^{\circ} \mathrm{C}$ and $1150{ }^{\circ} \mathrm{C}$.' Oxid. Met., 1983, 20, 255-278.

15. C. A. Barrett: 'The effects of $\mathrm{Cr}, \mathrm{Co}, \mathrm{Al}, \mathrm{Mo}$, and Ta on the cyclic oxidation behavior of a prototype cast Ni-base superalloy based on a $2^{5}$ composite statistically designed experiment,' NASA TM 8374, September, 1984. http://www.sti.nasa.gov/
16. A. Sato, Y. L. Chiu and R. C. Reed: 'Oxidation of nickel-based singlecrystal superalloys for industrial gas turbine applications,' Acta Mater., 2011, 59, 225-240.

17. R. C. Reed, J. Moverare, A. Sato, F. Karlsson and M. A. Hasselqvist: 'A new single crystal superalloy for power generation applications," in Proceedings of the 12th International Symposium on Superalloys, 9-13 September 2012, 197-204, TMS-AIME, Warrendale, PA.

18. R. A. MacKay, T. P. Gabb, J. L. Smialek and M. V. Nathal: 'A new approach of designing superalloys for low density,' JOM., 2010, 62, 48-54.

19. J. L. Smialek, A. Garg, T. P. Gabb and R. A. MacKay: 'Cyclic oxidation of high Mo, reduced density superalloys,' Metals., 2015, 5, 2165-2185. doi: http://dx.doi.org/10.3390/met5042165.

20. A. Karabela, et al: 'Effects of cyclic stress and temperature on oxidation damage of a nickel-based superalloy,' Mater. Sci. Eng. A., 2011, 528, 6194-6202.

21. J. L. Smialek and A. Garg: 'Interfacial reactions of a MAX phase/superalloy hybrid,' Surf. Interface Anal., 2015, 47, 844-853. (also NASA TM 2014-216679 1-19). doi: http://dx.doi.org/10.1002/sia.5784.

22. R. Nishii: 'Asymptotic properties of criteria for selection of variables in multiple regression,' Ann. Statist., 1984, 12, 758-765. http://projecteuclid. org/euclid.aos/1176346522

\section{Appendix. Summary of multiple linear regression results}

The results of the regression fit for the alloys in Table 3 are listed in Table A1. In addition to the coefficients for each significant term, the standard error, $t$-value and probability of exceeding the student's t parameter at a significance level associated with each is included. Diagnostics of this fit show that the residuals are fairly well behaved with no obvious outliers. Recognise that the inclusion of a term in the regression, if it is correlated with other terms, can alter the apparent influence of the correlated terms. Because the aluminium and chromium content are so tightly correlated, one cannot determine the relative influence of these elements with the commercial data-set. A means of determining the strength of the correlations in a multivariate data-set is the magnitude of the design matrix condition number. The design matrix for this set of experiments is a row-wise listing of the weight percentages of elements (+ interaction pairs) to be fit for each experiment in the data-set. This matrix must be inverted to solve for the regression coefficients. The condition number is simply the ratio of the largest and smallest eigen values of the design matrix. A large condition number indicates that two or more of the terms in the fit are tightly correlated with one another. Variance inflation factors can be computed for each term to determine which terms have the strongest interactions.

In addition, there exist criteria for selecting an appropriate number of terms in the regression. These criteria are designed to penalise models where additional terms add only marginal improvements to the 'goodness of fit'. An optimal model minimises the residual errors with a minimal number of terms. A commonly utilised criteria is called Akaike's Information Criterion or $\mathrm{AIC}^{22}$. A collection of functions written in $\mathrm{R}$ was coded to carefully select terms such that the AIC was minimised while the condition number of the design matrix and variance inflation factors were monitored (analogous to selecting only weakly correlated variables). 


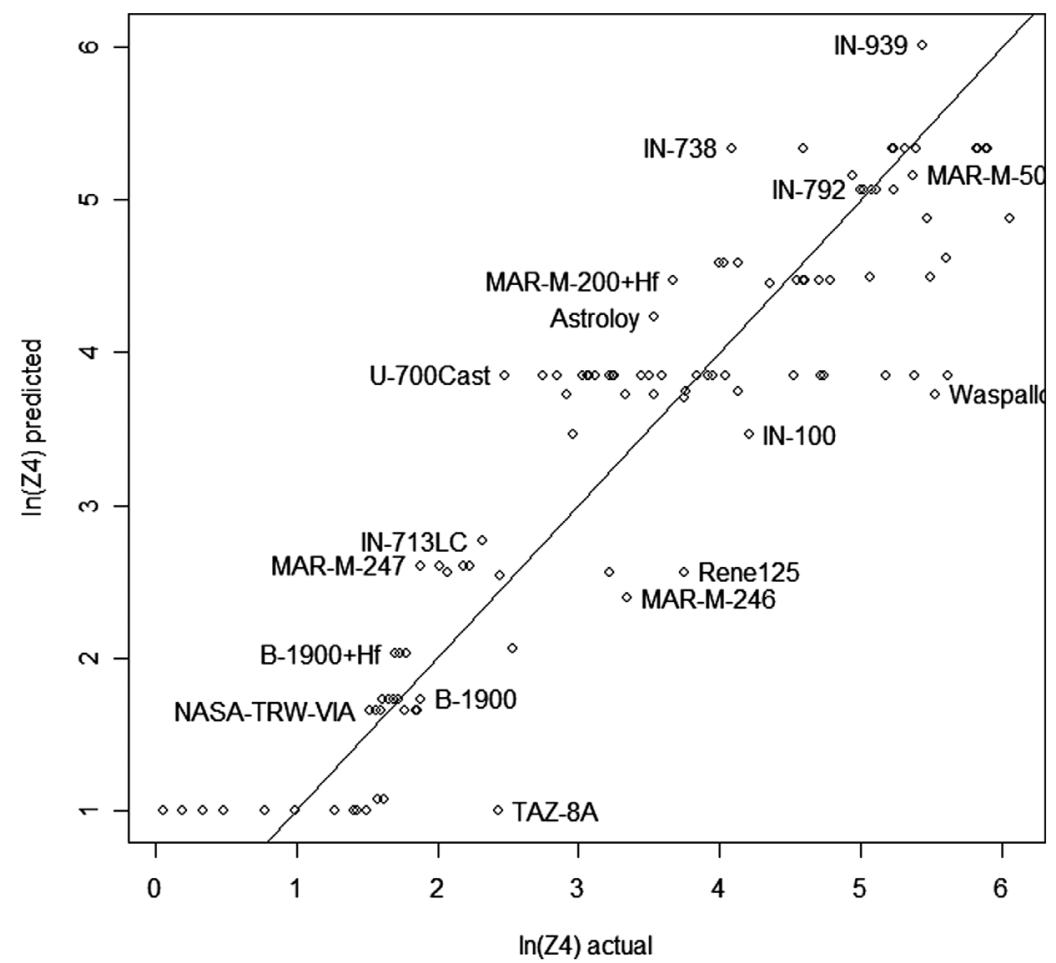

Figure A1 Correlation of predicted vs. actual Z4 weight change transform, showing spread in duplicate test results

Table A1 Compositional coefficients and statistical significance for regression fit parameters, In(Z4)

\begin{tabular}{|c|c|c|c|c|}
\hline & Estimate & Std. Error & $t$ value & $\operatorname{Pr}(>|t|)$ \\
\hline (Intercept) & 5.1067 & 0.8465 & 6.03 & $2.81 \mathrm{E}-08^{\text {twt }}$ \\
\hline Al & -0.6061 & 0.1399 & -4.33 & $3.57 \mathrm{E}-05^{4+t}$ \\
\hline $\mathrm{Ti}$ & 0.3094 & 0.0976 & 3.17 & $0.0020^{+*}$ \\
\hline Ta:Mo & -0.0316 & 0.0090 & -3.51 & $0.00068^{*+*+}$ \\
\hline $\mathrm{Ti}: \mathrm{Nb}$ & 0.3372 & 0.0743 & 4.54 & $1.60 \mathrm{E}-05^{\text {t.* }}$ \\
\hline Ta:Hf & -0.3166 & 0.0683 & -4.64 & $1.06 \mathrm{E}-05^{t+1+}$ \\
\hline $\mathrm{C}: \mathrm{W}$ & 1.1974 & 0.1481 & 8.09 & $1.57 \mathrm{E}-12$ \\
\hline $\mathrm{Nb}: \mathrm{W}$ & -0.064 & 0.0235 & -2.73 & $0.0075^{*+}$ \\
\hline Al:Mo & 0.0241 & 0.0053 & 4.59 & $1.28 \mathrm{E}-05^{*+*}$ \\
\hline C:Co & -0.1535 & 0.0367 & -4.19 & 6.07E-05 \\
\hline Mo:Hf & 0.2772 & 0.0944 & 2.94 & $0.0041^{* *}$ \\
\hline
\end{tabular}

Notes: Signif. codes: $0.0^{\cdots *} ; 0.001^{*} ; 0.01^{*}$. Residual standard error: 0.6667 on 99 degrees of freedom. Multiple $R^{2}$ : 0.8358 , Adjusted $R^{2}$ : 0.8192. F-statistic: 50.39 on 10 and 99 DF, $p$-value: $<2.2 e-16$. 